\title{
Effects of intrastimulus modality change on audiovisual time-to-arrival judgments
}

\author{
MICHAEL S. GORDON and LAWRENCE D. ROSENBLUM \\ University of California, Riverside, California
}

\begin{abstract}
In this research, anticipatory perception of an approaching vehicle was examined. By varying the availability of visual and acoustic media, conditions occurred in which the input to the modalities was repetitively interrupted while the presentation of the approach event continued. In these conditions, the audio and the visual signals were presented either in short and concurrent segments at regular intervals or in alternation (interleaved) at regular intervals. It was found that interrupting the signal within a single modality did not affect performance if the approach information was available in the alternate modality. These results are consistent with a modally flexible detection mechanism for the perception of approaching objects. This modal flexibility may provide some evidence that information is detected using a modality-neutral strategy.
\end{abstract}

While driving, a perceiver may detect an ambulance approaching. The visual and acoustic signals structured by the approach of the ambulance may be used to inform the perceiver about its impending time to arrival (TTA $)^{1}-$ that is, the time at which the ambulance would reach his or her position. Several studies have demonstrated the utility of visual and acoustic information for TTA judgments (e.g., Cavallo \& Laurent, 1988; Gordon, 2003; Gray \& Regan, 1998; Hancock \& Manser, 1997; Rosenblum, Carello, \& Pastore, 1987; Rosenblum, Gordon, \& Wuestefeld, 2000; Schiff \& Oldak, 1990). Typically, these judgments entail the subject's seeing or hearing an object approaching his or her position (e.g., Cavallo \& Laurent, 1988; Hancock \& Manser, 1997; McLeod \& Ross, 1983; Rosenblum, Gordon \& Wuestefeld, 2000; Rosenblum, Wuestefeld, \& Saldaña, 1993; Schiff \& Detwiler, 1979; Schiff \& Oldak, 1990). In response, the subject is asked to judge the moment the object reaches his or her position - or would have reached the position if it vanishes en route.

To correctly judge these events, the subject must indicate the approaching object's passage point by pressing a key at that moment (as will be the case in the following study). The passage point refers specifically to the moment at which an object reaches an observer and begins

This research was funded by a University of California Graduate Dean's Dissertation Research Grant, an Intramural Research Grant from the University of California, and National Science Foundation Grant 0111949. We gratefully acknowledge the assistance of George J. Andersen and Asad Saidpour, for their guidance with the visual stimulus presentations, and of several dedicated research assistants: Debbie Ha, Susie Haggag, Lona Ishigaki, Phuc Phung, and Reham Shaath. We also thank Mari Riess Jones, Timothy Hubbard, Peter Hancock, and an anonymous reviewer for their comments on this manuscript. Correspondence concerning this article should be addressed to M. S. Gordon, Department of Psychology, University of Toronto, 3359 Mississauga Rd. N., Mississauga, ON, LSL 1C6 Canada (e-mail: mgordon@utm. utoronto.ca). to pass by. The passage point is also commonly the location at which the recording equipment is positioned or, for simulated events, the point at which the virtual observer is located.

Interestingly, some analogous findings in visual and acoustic TTA research have suggested that a common form of information, tau, may underlie detection in both modalities (Rosenblum, 1993; Rosenblum \& Gordon, 2001; Shaw, McGowan, \& Turvey, 1991; but see Guski, 1992). In the present experiments, these issues were examined by testing the mutual use of audio and visual TTA information. These experiments tested the flexibility of perception in the use of information from visual and acoustic media (and their associated modalities) for detection of a single TTA event.

Although much is known about unimodal auditory and visual TTA, very little research has addressed multimodal detection and integration for this paradigm (e.g., DeLucia, Kaiser, Bush, Meyer, \& Sweet, 2003; Gordon, 2003; Morrongiello \& Fenwick, 1991; Pickens, 1994; Schiff \& Oldak, 1990). In previous studies on multimodal TTA perception, unaltered visual and audiovisual stimuli presentations were found to support equally accurate performance, whereas performance with unimodal audio stimuli supported somewhat worse performance (Gordon, 2003; Schiff \& Oldak, 1990). In general, errors tended to be underestimations of the TTA - a finding that has been well replicated in the unimodal studies on both modalities (for reviews, see Hancock \& Manser, 1998; Rosenblum, 1993).

In other audiovisual TTA experiments, the effects of degrading the fidelity of the stimuli have been examined using masking noise (Gordon, 2003). In low to moderate levels of both auditory and visual noise, performance with audiovisual stimuli was generally found to be equivalent to unimodal performance with one of the contributing media. For example, if a bimodal stimulus was constructed of a low-noise audio and a moderate-noise 
visual component, performance with the audiovisual stimulus would tend to be analogous to performance with the unimodal low-noise audio stimulus. When both the visual and the acoustic stimuli were embedded in very high levels of noise, bimodal performance was better than that found with either of the contributing unimodal components (Gordon, 2003). These experiments may suggest a somewhat flexible usage of TTA information with regard to modality; as the noise-related degradation to the audio and visual signals varied, the reliability and salience of the contributing modal inputs seemed to also vary. When both the audio and the visual signals were severely degraded by noise and presented bimodally, audiovisual enhancement was observed (Gordon, 2003).

The audiovisual TTA findings suggest the contribution of both visual and acoustic input for judgments, as well as perceptual flexibility with regard to the more salient modality within a multimodal signal. If the information for TTA has a similar form across modalities, it would not be surprising to find a modal flexibility for the detection of TTA. In fact, for both visual and auditory contexts, a tau informational variable has been discussed as supporting TTA judgments (Gordon, 2002; Lee, 1990; Rosenblum, 1993; Shaw et al., 1991). Tau may be defined as an informational variable that specifies the amount of time before an object reaches an observer, as derived from the inverse rate of change of a sensory dimension (for discussions, see Lee, 1976, 1990; Shaw et al., 1991; Tresilian, 1991). For example, tau equations have been applied to optical expansion and the increase of acoustic intensity. Tau has been speculated as a single, modality-neutral variable (i.e., TTA) or as a collection of separate but related variables instantiated in different media (for discussions, see Cabe \& Pittenger, 2000; Kaiser \& Mowafy, 1993; Lee, 1990; Rosenblum \& Gordon, 2001).

In order to test the flexibility with which TTA information can be used across modalities, an intrastimulus switching technique was applied to the TTA paradigm. This technique involved rapidly changing the available modality information within a given presentation. To the extent that the information can be used flexibly, it would be predicted that the continuity of the information about an event, rather than the continuity of the presentation within a particular modality, would be most salient for TTA perception. In other words, alternation between audio and visual modal information within an approach event should have a relatively small effect on TTA judgment accuracy.

\section{EXPERIMENT 1 Audiovisual Intrastimulus Modality Switching}

The first experiment tested the flexible use of modalities by comparing TTA performance across three stimulus conditions (see Figure 1). In the intermittent condition, both the event and the individual modalities were concurrently interrupted by presenting the audio and the visual signals interspersed with visually blank and acoustically silent segments. In the alternating condition, the modalities, but not the event, were interrupted by alternating the presentation of the visual and the audio signals. In the normal condition (control), the audio and the video signals were presented intact, so that neither the event nor the modalities were interrupted. If perceivers are able to use the modalities flexibly for TTA perception, only the intermittent condition, which interrupts the event, should degrade performance. The interruption of the modalities, but not the event, in the alternating condition would not be expected to disrupt performance, relative to the normal control condition.

All manipulations were made on field recordings of an approaching vehicle (see, e.g., Schiff \& Oldak, 1990). Natural binaural audio recordings were chosen because they have been found to conserve much of the acoustic structure from the original environment (Blauert, 1997/ 1999; Gilkey \& Anderson, 1997; Hawley, Litovsky, \& Colburn, 1999; Minnaar, Olesen, Christensen, \& Møller, 2001; Yost, Dye, \& Sheft, 1996). To correspond with these binaural recordings, visual stimuli were filmed (videotaped) simultaneously. Although filmed visual stimuli are less commonly used than animated stimuli in TTA research, several experiments have shown filmed stimuli to support accurate judgments (e.g., Cavallo \& Laurent, 1988; McLeod \& Ross, 1983; Schiff \& Detwiler, 1979; Schiff \& Oldak, 1990). Because of the novelty of the intrastimulus technique, several additional variables were tested to ensure that performance in these experiments would be comparable to that in previous TTA research. To this end, manipulations were made of the approach velocity of the vehicle (e.g., Hancock \& Manser, 1997; McLeod \& Ross, 1983; Rosenblum, Gordon, \& Wuestefeld, 2000; Schiff \& Detwiler, 1979), as well as the stimulus onset time and offset time (truncation) of the presentation prior to the object's arrival (e.g., Hancock \& Manser, 1997; Rosenblum, Gordon, \& Wuestefeld, 2000; Schiff \& Detwiler, 1979; Sidaway, Fairweather, Sekiya, \& McNitt-Ray, 1996).

\section{Method}

Subjects. Eight students (5 women and 3 men) from the University of California, Riverside, participated in this experiment for class credit. All the subjects reported good hearing (without correction) and good vision (some with corrective lenses). Although all the subjects were naive as to the purposes of this experiment, 4 had previously participated in TTA experimentation that did not involve the intrastimulus switching technique. These 4 subjects were reused because of limited subject availability at the time of testing. Postexperimental statistical testing revealed no differences between these two groups of subjects.

Design. Four independent variables were manipulated for this experiment: the intrastimulus modality condition (three levels: normal, alternating, or intermittent), the speed of the looming vehicle (three levels: 5,15 , or $25 \mathrm{mph}$; i.e., $8.05,24.14$, or $40.23 \mathrm{~km} / \mathrm{h}$ ), the stimulus onset time of the TTA presentation before reaching the passage point (three levels: presentation started 3, 5, or $7 \mathrm{sec}$ before the point of passage), and the elapsed time between the moment at which the target vanished and the point of passage (i.e., truncation; 


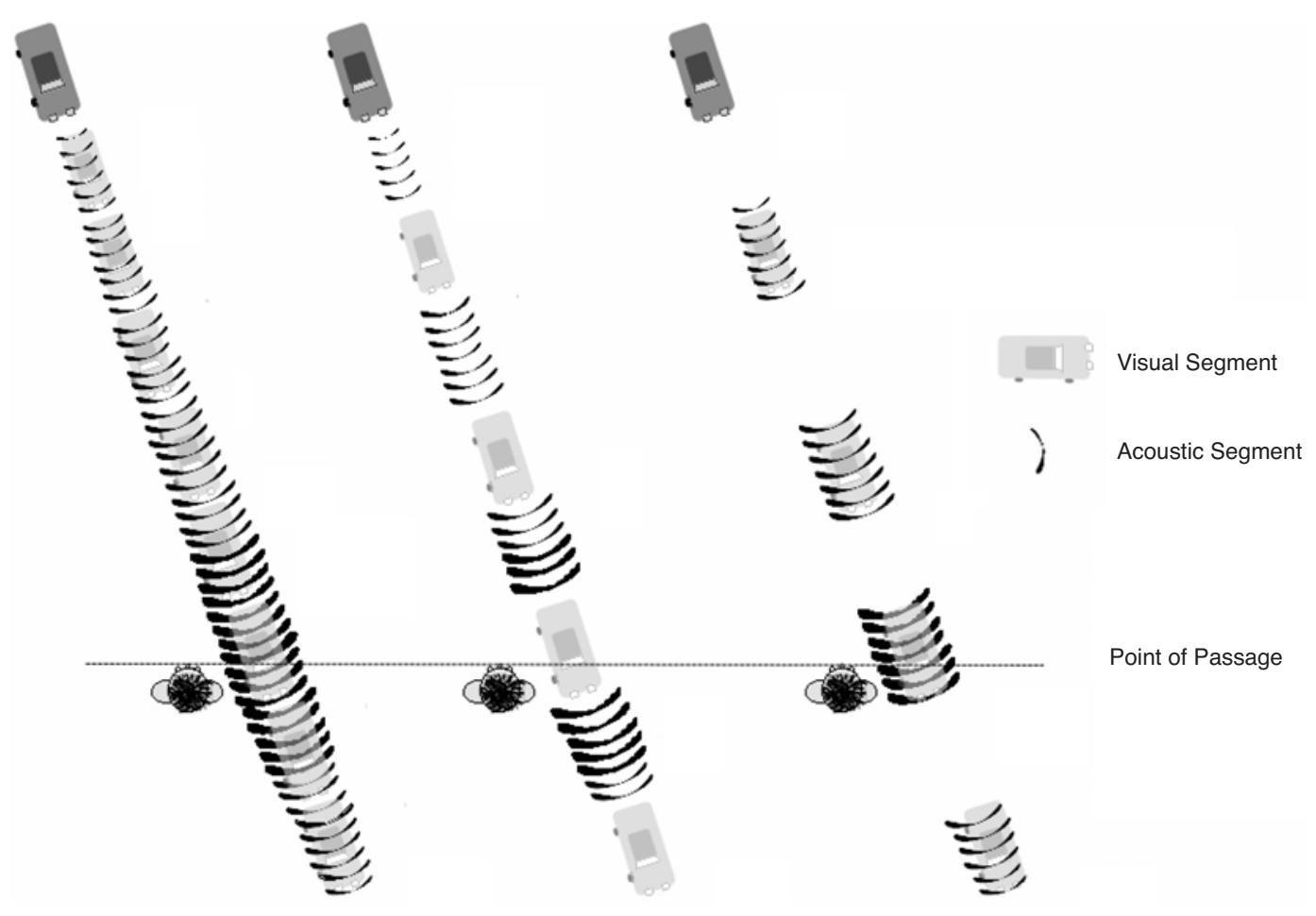

Figure 1. Schematics of the normal (left), alternating (middle), and intermittent (right) intrastimulus switching conditions. The number of actual segments presented was varied by the approach and truncation times. In the alternating condition, a visual segment always immediately preceded the point of passage. In the intermittent condition, an audiovisual segment immediately preceded the point of passage.

three levels: full passage, $1 \mathrm{sec}$, or $2 \mathrm{sec}$ ). These three levels of stimulus onset and truncation time resulted in actual presentation times that varied between $1 \mathrm{sec}$ (i.e., 3 -sec stimulus onset with a 2 -sec truncation) and $9 \mathrm{sec}$ (i.e., 7 -sec stimulus onset to the passage point, followed by an additional $2 \mathrm{sec}$ of presentation after the object surpassed the point of passage in the full-length trajectories). All the variables were tested within subjects and were presented together in a fully randomized design.

Materials. The visual recordings were made using a Sony DRCTRV11 digital video camcorder attached to a tripod that was set at a height of $1.91 \mathrm{~m}$. For each recording, the approach vehicle (1999 Toyota Corolla) was driven at a constant velocity and passed the recording instruments on the right at a distance of approximately $0.8 \mathrm{~m}$. Previous research has demonstrated that very close bypass presentations (as used in the present research) are judged as accurately as collision trajectories (Kaiser \& Mowafy, 1993; Schiff \& Oldak, 1990). The recording instruments remained stationary during filming, so that the vehicle moved across the scene at an angle of approximately $30^{\circ}$ relative to the point of observation, starting in the front-left quadrant of the screen, then passing the observer on the right (see Figure 1). The subjects were asked to adopt the vantage of the camera's point of observation in order to make judgments about the approaching vehicle. As a bypass trajectory, the closer the object got to the point of observation, the more lateral the object became in the visual scene of the perceiver, until leaving the scene just prior to passage. This increasing lateral difference (commonly referred to as global tau) is itself a useful source of TTA information (see Kaiser \& Mowafy, 1993, for a discussion).

The vehicle was mounted with a Radio Shack two-tone siren, Part BP 4952. The acoustic signal generated by this siren ranged from $45 \mathrm{~dB}$ SPL at the farthest distance to $83 \mathrm{~dB}$ at the closest po- sition. The siren was a complex tone that modulated between 865 and $1730 \mathrm{~Hz}$, with a $500-\mathrm{msec}$ rise time and a $30-\mathrm{msec}$ fall. The intensity of the signal was found to rise exponentially, with its slope dependent on the velocity of the approaching vehicle. At $5 \mathrm{mph}$, the exponent of the slope was approximately 0.39 ; at $15 \mathrm{mph}$, the slope rose to approximately 1.15 ; and at $25 \mathrm{mph}$, the slope neared 1.91 . This siren sound was selected to simulate the paradigm first described in this article - the experience of a perceiver being approached by an ambulance (see also Caelli \& Porter, 1980; Rosenblum et al., 1987). This two-tone siren approximated the sirens used locally by emergency vehicles at the time of testing. Auditory stimuli were binaural recordings taken by placing two small SoundPro SP-MICRO-1 microphones $(0.5-\mathrm{cm}$ diameter) in the ears of an adult male ( $1.82 \mathrm{~m}$ tall; $102.1 \mathrm{~kg})$. These microphones were relayed through a custom SoundPro preamplifier into a Sony TCD-D8 Digital Audio Tape recorder that captured the sound.

The recorder's head was positioned at the lower right edge of the video camera. The placement of the recorder's head positioned the lens of the camera approximately $9 \mathrm{~cm}$ above the recorder's right eye. The binaural recording technique was used because of its ability to capture acoustic characteristics, such as interaural differences, pinna filtering, and body/head shadowing, to create a spatial soundscape (Blauert, 1997/1999; Gilkey \& Anderson, 1997; Hawley et al., 1999; Minnaar et al., 2001; Yost et al., 1996). Because simultaneous capture was made of the audio and the visual stimuli, the camera's position did have some influence on the acoustic structure of the scene. Specifically, the camera added a reflective surface on the right side of the observer's head, increasing the amount of reverberant energy for the right ear. Comparison between the two ears revealed that, on average, the total power of the signal in the right ear was $1.03 \mathrm{~dB}$ greater than that for the left ear. Thus, the use of 
this simultaneous capture method ensured the synchronicity of the audio and the visual components, with minimal change to the acoustic realism of the recordings.

Later, the audio and visual recordings were digitally captured onto computer, using Adobe Premier 6.0 software for Macintosh. Audiovisual pairings were synchronized by use of a customdesigned camera synchronization slate (or clapper board), and only simultaneously captured recordings were combined for presentations. Macromedia Authorware 4.0.3 for Macintosh was used to present the stimuli to the subjects and to record TTA judgments.

As was mentioned, the speed of the approaching vehicle was varied (see, e.g., DeLucia \& Liddell, 1998; Gray \& Regan, 1998, 1999; Rosenblum et al., 1987; Rosenblum, Gordon, \& Wuestefeld, 2000; Schiff \& Detwiler, 1979; Schiff \& Oldak, 1990). Three vehicle approach velocities were used: $5 \mathrm{mph}(8.05 \mathrm{~km} / \mathrm{h}), 15 \mathrm{mph}(24.14 \mathrm{~km} / \mathrm{h})$, and $25 \mathrm{mph}(40.23 \mathrm{~km} / \mathrm{h})$. The approach velocities were selected from within the range previously used in audio and visual TTA experiments (e.g., Kaiser \& Mowafy, 1993; McLeod \& Ross, 1983; Rosenblum, Gordon, \& Wuestefeld, 2000; Rosenblum et al., 1993; Schiff \& Detwiler, 1979; Schiff \& Oldak, 1990; Sidaway et al., 1996). Constant velocity was ensured using two methods. At the time of recording, the vehicle accelerated to the test velocities and maintained speed, using the speedometer. The acceleration portion of these recordings was not used in testing. The speeds were later reconfirmed from the recordings by measuring the duration of the vehicle's movement across a known distance.

Three levels of the truncation variable were created using Premiere editing software. Full-length passages were presentations of the vehicle approaching and passing the observer to continue for an additional $2 \mathrm{sec}$. For the 1 -sec truncation, the vehicle vanished $1 \mathrm{sec}$ prior to passage, and for the 2-sec truncation, the vehicle vanished $2 \mathrm{sec}$ prior to passage. These truncation times were taken from the typical range used in time-to-passage experiments (e.g., Hancock \& Manser, 1997; Kaiser \& Mowafy, 1993; Rosenblum, Gordon, \& Wuestefeld, 2000; Schiff \& Oldak, 1990). A visually gray screen and acoustic silence followed truncation.

The stimulus onset of each event was also varied. Stimulus onset refers to when the vehicle (and stimulus) first appeared, relative to when the vehicle would have reached the passage point. Three values of stimulus onset were used: 3,5 , and $7 \mathrm{sec}$; these stimulus onsets are well within the range of many TTA experiments (e.g., Cavallo \& Laurent, 1988; Heuer, 1993; McLeod \& Ross, 1983; Rosenblum, Gordon, \& Wuestefeld, 2000; Schiff \& Detwiler, 1979; Schiff \& Oldak, 1990; Sidaway et al., 1996). Stimulus onset and truncation were independently varied according to the passage point. Given the three speeds and stimulus onsets used in this experiment, the range of actual approach distances varied from about 20 to $250 \mathrm{ft}$ (6-76 m).

The presentation conditions were designed as follows (Figure 1). The alternating conditions alternated between audio and visual signals during a given event. The subjects experienced a concatenated string of 500 -msec visual segments, alternated with $500 \mathrm{msec}$ of the audio segments. At no point were audio and visual segments presented simultaneously for the alternating conditions. Thus, for the visual component of the stimulus, an observer was presented $500 \mathrm{msec}$ of visual signal, then $500 \mathrm{msec}$ of a blank segment, followed by $500 \mathrm{msec}$ of signal, and so forth. Simultaneously with this visual stimulus, the opposite pattern was presented in the auditory signal ( $500 \mathrm{msec}$ of a silent segment, followed by $500 \mathrm{msec}$ of signal, etc.). This editing resulted in presentations such as the following. Upon stimulus onset, the visual signal appeared and lasted for a segment between 2.5 and $2.0 \mathrm{sec}$ TTA (before passage). At $2.0 \mathrm{sec}$ TTA, the visual stimulus was turned off, and the auditory stimulus was presented and lasted until $1.5 \mathrm{sec}$ TTA. At $1.5 \mathrm{sec}$ TTA, the auditory stimulus was turned off, and the visual stimulus was presented until $1.0 \mathrm{sec}$ TTA. This alternating pattern continued until the trial's end. Importantly, each 500-msec segment of both visual and auditory signal presented the appropriate segment for the par- ticular portion of the trajectory that was being indicated (e.g., the visual segment between 1.5 and $1.0 \mathrm{sec}$ TTA showed the car traversing the appropriate distance for that time period in the trajectory). Thus, the approach events were portrayed in a continuous fashion, even though the modality of presentation alternated (see Figure 1). For all the alternating stimuli, the visual segment immediately preceded truncation. When the video signal went off, it was replaced by a gray screen isoluminant to the visual signal (e.g., Anderson \& Vingrys, 2000; Takahashi \& Maruyama, 1977). When the auditory signal went off, it was replaced by silence (see Wiegrebe $\&$ Krumbholz, 1999, for a discussion of acoustic masking). These parameters of the blank segments were chosen to reduce visual and auditory distraction while the signals were not present. The 500msec segment length was used on the basis of pilot studies and evidence suggesting that this duration was sufficient to suppress apparent motion (Hock, Kogan, \& Espinoza, 1997; Petersik, 1989). Again, the audiovisual alternating trials presented a continuous TTA event, but the modality signal carrying the presentation was switched at regular intervals.

In contrast, the intermittent conditions alternated a $500-\mathrm{msec}$ segment involving the simultaneous presentation of auditory and visual signals with a 500-msec blank/silent segment (blank/silent segments were the same as those described for the alternating presentations). Thus, the intermittent conditions disrupted the continuity of the event, as well as the available media, by the insertion of the blank segments. The intermittent conditions started with the audiovisual signal, and when truncated, the stimuli were edited so that the audiovisual signal presentation always immediately preceded the offset of the presentation. This editing did not affect the truncation or presentation durations in any way. As with the alternating presentations, the signals were advanced during the blank segments. This editing resulted in presentations such as the following. Upon stimulus onset, the audiovisual stimulus appeared and lasted for a segment between 2.5 and $2.0 \mathrm{sec}$ TTA (before passage). At $2.0 \mathrm{sec}$ TTA, both the audio and the visual components were turned off until $1.5 \mathrm{sec}$ TTA. At $1.5 \mathrm{sec}$ TTA, the audiovisual stimulus was turned back on and was presented until $1.0 \mathrm{sec}$ TTA. This alternating pattern continued until the trial's end. Importantly, each 500msec segment of the audiovisual signal presented the appropriate segment for the particular portion of the trajectory that was being indicated (e.g., the audiovisual segment between 1.5 and $1.0 \mathrm{sec}$ TTA showed the car traversing the appropriate distance for that time period in the trajectory). It should be noted that although very different in relative timing, the intermittent and the alternating stimuli involved the same amount of audiovisual and visual signal. Moreover, the visual segments from the alternating presentations corresponded exactly with the visual component of the audiovisual presentations in the intermittent presentations.

The normal conditions consisted of unaltered audiovisual presentations of the approaching vehicle. Audio and visual signal components were congruously presented throughout the presentation, within the specific constraints of the truncation and stimulus onsets discussed above.

Procedure. The subjects were asked to watch and listen to a recording of a car driving toward their point of observation (e.g., Cavallo \& Laurent, 1988; Hancock \& Manser, 1997; McLeod \& Ross, 1983; Rosenblum, Gordon, \& Wuestefeld, 2000; Rosenblum et al., 1993; Schiff \& Detwiler, 1979; Schiff \& Oldak, 1990). In response to each presentation, the subjects were asked to press a key the moment the vehicle reached - or would have reached - their position.

At the beginning of each experiment, the subjects were given a brief description of the task. They were told that on each trial, they would be presented an acoustic and/or a visual display of a car driving toward them. This car might reach and surpass their position or vanish while on approach. If the vehicle vanished prior to arrival, the subjects were instructed to respond as if the vehicle had continued on the same path and speed (see, e.g., Gray \& Regan, 1998; Rosenblum, Gordon, \& Wuestefeld, 2000; Schiff \& Oldak, 1990). 
The moment the vehicle reached their position (or would have reached their position had it not vanished en route), the subjects were to press a key indicating that point of passage.

Prior to the critical tests, a 25 -trial training session with feedback was given. This type of training is commonly used in both visual and auditory TTA experiments to familiarize subjects with the task and the passage point (e.g., DeLucia \& Novak, 1997; Heuer, 1993; Kaiser \& Mowafy, 1993; Rosenblum et al., 1987; Rosenblum, Gordon, \& Wuestefeld, 2000; Schiff \& Oldak, 1990). The training trials were not analyzed with the results. Training consisted of a randomized combination of 4 normal audiovisual trials, 3 audiovisual alternating trials, 3 audiovisual intermittent trials, 5 unimodal visual trials, and 10 unimodal acoustic trials. Of these 15 audio and visual unimodal trials, 3 of the visual and 5 of the acoustic were presented intermittently (i.e., every other 500 -msec segment was replaced by a blank segment). These unimodal intermittent stimuli were presented only during the training session and were used to improve the subjects' familiarity with both the visual and the acoustic intrastimulus switching presentations in isolation. The stimuli in the training were varied randomly across all levels of speed, approach, and truncation. The larger number of unimodal acoustic trials, relative to unimodal visual trials, were included because of previous research suggesting greater difficulty with TTA auditorily than visually (Schiff \& Oldak, 1990).

During the training period, the subjects received a text message with feedback after each trial. One of three feedback messages was presented on the basis of the following guidelines: Responses made earlier than $45 \mathrm{msec}$ prior to passage were given the feedback label early, responses made within $90 \mathrm{msec}$ of the passage point $(45 \mathrm{msec}$ before or after) were labeled on time, and responses made $45 \mathrm{msec}$ or more after the passage point were labeled late.

Immediately following the training, the subjects began the critical testing session. No feedback was given during the critical test session (see, e.g., DeLucia \& Novak, 1997; Heuer, 1993; McLeod \& Ross, 1983; Schiff \& Detwiler, 1979; Schiff \& Oldak, 1990). The subjects received three iterations of each of the 81 possible conditions ( 3 presentation conditions $\times 3$ speeds $\times 3$ truncation lengths $\times$ 3 stimulus onsets), for a total of 243 trials. The total session length was $45-50$ min per subject.

The visual stimuli were displayed at $30 \mathrm{fps}$ in grayscale (see, e.g., Schiff \& Detwiler, 1979). The stimuli were presented using a Macintosh G4 966 Power PC workstation. The visual stimuli were displayed to the subjects on a ViewSonic G90f, 19-in. CRT flat screen monitor, visually projected at $1,020 \times 680$ pixels on a screen of resolution $1,024 \times 1,280$. The monitor had a refresh rate of $75 \mathrm{~Hz}$. The visual angle of the display to the subject was $14.16^{\circ}$ (height) $\times$ $16.42^{\circ}$ (width). The stimuli were viewed through a glass planoconvex collimating lens with a $16 \%$ magnification, expanding the image to $20.90^{\circ}$ (height) $\times 24.24^{\circ}$ (width). This collimating lens was used to reduce aberrant convergence cues and increase the impression of depth within the visual scene (see, e.g., Andersen, Saidpour, \& Braunstein, 1998; Chase, 1970; Gordon, 2003). A lens $20 \mathrm{~cm}$ in diameter was placed $75 \mathrm{~cm}$ from the monitor. A chinrest held the subjects at a viewing distance of $85 \mathrm{~cm}$ from the monitor. These specifications were set according to the focal distance of the lens.

The acoustic, binaural stimuli were played to the subjects through high-quality Sony MDR-V600 stereo headphones. Both the visual and the auditory stimuli were presented to the observer directly from the computer.

\section{Results and Discussion}

Approximately $85 \%$ of all the responses were underestimations of the amount of time before passage (i.e., the subjects most often responded that the car would have reached them earlier than the actual time of passage). Underestimations are commonly observed in TTA research (see Hancock \& Manser, 1998, for a review). Analyses were conducted to determine whether this pattern in the proportion of underestimations was consistent across the independent variables (intrastimulus conditions, speed, truncation, and stimulus onset). The results revealed that within each of these conditions, the pattern of underestimation was not found to statistically vary.

Prior to analysis, all of the judgments that were inaccurate by more than $2.5 \mathrm{sec}$ were removed from the data set. These aberrant judgments constituted fewer than $1 \%$ of the trials and were caused mostly by the computer response system timing out - that is, these late responses were not recorded during the presentation of a trial. A repeated measures analysis of variance (ANOVA) was used to determine accuracy within this experiment. Accuracy was measured by the absolute deviation of each response from the actual passage point (Kaiser \& Hecht, 1995; Rosenblum, Gordon, \& Wuestefeld, 2000; Rosenblum et al., 1993; Sidaway et al., 1996). Absolute deviation scores were considered the best measure of performance because of the tendency of the subjects to underestimate the arrival of the approaching object. Given this underestimation, analyses using a signed (nonabsolute) measure of deviation could reduce the total reported error. For example, if two judgments were $-500 \mathrm{msec}$ (underestimation) and $100 \mathrm{msec}$ (overestimation), it would produce an absolute deviation of $300 \mathrm{msec}$ and a signed error of $-200 \mathrm{msec}$. In this example, the average error of the signed values is $66 \%$ less than that of the absolute values. Thus, for the present experiments, the unsigned, absolute deviation scores were used for all the analyses, to best represent the total error.

Condition effects. Comparisons across intrastimulus modality conditions revealed that judgments were more accurate with the normal (i.e., unaltered control condition) and alternating conditions than with the intermittent conditions $\left[F(2,14)=6.82, M S_{\mathrm{e}}=0.048, p<.025\right.$; see Figure 2]. Paired comparisons revealed differences between normal and intermittent conditions $[F(1,7)=$ 13.07, $\left.M S_{\mathrm{e}}=0.048, p<.01\right]$ and between alternating and intermittent conditions $\left[F(1,7)=6.07, M S_{\mathrm{e}}=0.048\right.$, $p=.0488]$. These differences are relatively small effects, as compared with some of the other variables tested; however, they are also very consistent effects. Individual analyses of the subjects revealed that the intermittent conditions were judged less accurately than the normal and alternating conditions for all but 1 of the tested subjects. Thus, although the total difference between the normal and alternating versus the intermittent conditions is $33 \mathrm{msec}$ (as is shown in Figure 2), removal of this 1 aberrant subject increases the mean difference to $88 \mathrm{msec}$. Without the aberrant subject, the accuracy improvement between these conditions is comparable to the other TTA effects in this and other experiments (see Hancock \& Manser, 1998, for a review). No difference was found between normal and alternating conditions $[F(1,7)=$ $\left.1.32, M S_{\mathrm{e}}=0.048, p>.2\right]$. This pattern of results suggests the relative flexibility of TTA perception in using information from multiple modalities. In particular, per- 


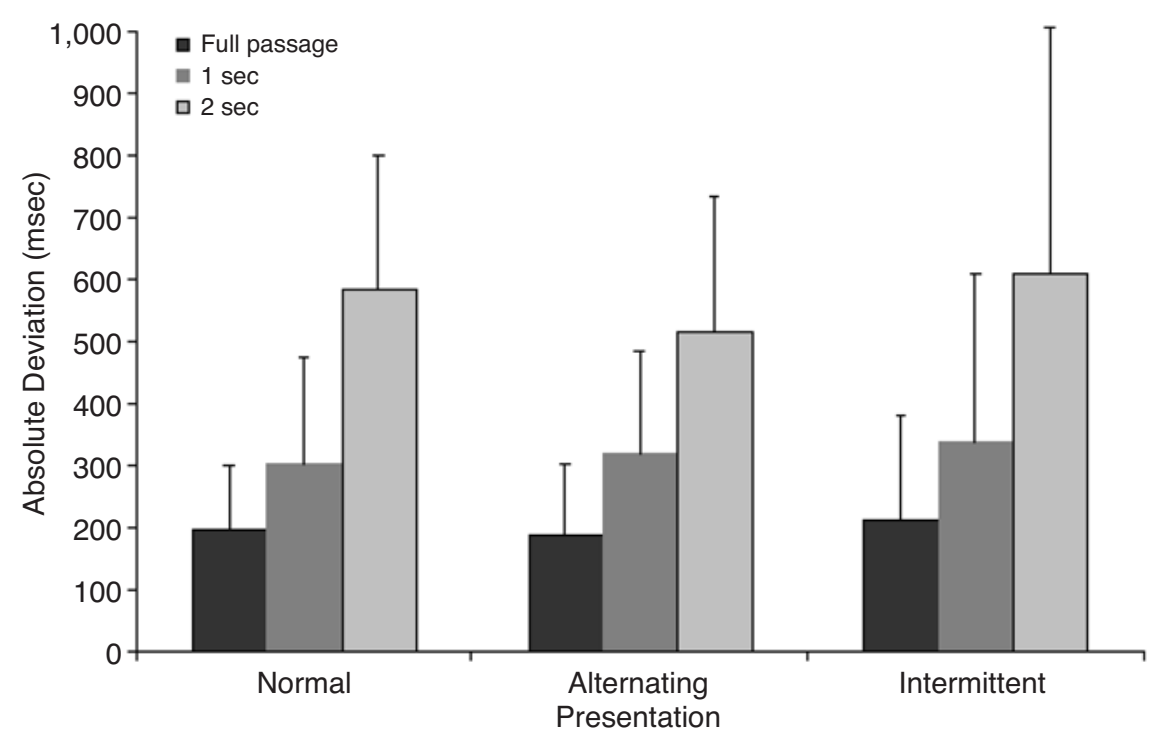

Figure 2. Absolute deviation of responses by condition type and truncation in Experiment 1. Error bars give the standard deviations of judgments.

formance with the alternating condition suggests that the constancy of the event information may be detected even across changes in the modality of presentation.

Truncation, speed, and approach. There was an overall effect of truncation length; longer truncations generally diminished performance accuracy, relative to shorter truncations $\left[F(2,14)=17.455, M S_{\mathrm{e}}=0.176\right.$, $p<.001$; see Figure 2]. Full-length passages supported better accuracy than 1 -sec truncations did $[F(1,14)=$ $\left.5.75, M S_{\mathrm{e}}=0.176, p<.05\right], 1-\mathrm{sec}$ truncations supported better accuracy than 2 -sec truncations did $[F(1,14)=$ $\left.15.62, M S_{\mathrm{e}}=0.176, p<.005\right]$, and full-length passages supported better accuracy than 2 -sec truncations did $\left[F(1,14)=40.323, M S_{\mathrm{e}}=0.176, p<.001\right]$. These truncation results are consistent with findings in previous TTA research (for reviews, see Hancock \& Manser, 1998; Rosenblum, 1993).

To address concerns about whether performance with the full-length passage stimuli did reflect accurate TTA performance, a goodness-of-fit test was conducted (see Pressing, 1998, for a discussion). The observed data were binned (i.e., divided) into two categories: absolute deviation scores less than $200 \mathrm{msec}(0-199 \mathrm{msec})$ and absolute deviation scores greater than $200 \mathrm{msec}(200 \mathrm{msec}$ and up). Ideal performance for the full-length passages was assumed to be centered in the 0 - to 199 -msec range ( $90 \%$ of the responses were within this criterion), and it was assumed that there would be a normal distribution of errors spreading into the over-200-msec bin. Generally, performance was not found to vary from the assumed ideal $\left[\chi^{2}(2)=3.43, p>.05\right]$. This fitness suggests that, at least with the full-length passage stimuli, the subjects were able to perform this task with very high accuracy.

Small differences in performance were found between the velocities $\left[F(2,14)=4.194, M S_{\mathrm{e}}=0.078, p<.05\right]$.
The 15-mph presentations tended to be judged more accurately than the 25 -mph presentations $[F(1,14)=5.436$, $\left.M S_{\mathrm{e}}=0.078, p<.05\right]$. No other speed comparisons reached significance. There were no main effects of stimulus onset. Generally, these results are consistent with previous TTA judgments (for reviews, see Hancock \& Manser, 1998; Rosenblum, 1993).

The replication of previous TTA results also suggests the feasibility of using high-quality natural acoustic stimuli for testing. Although there has been TTA experimentation with stereo acoustic presentations (e.g., Neuhoff, 2001; Rosenblum et al., 1987), acoustic binaural recordings have not previously been applied to this paradigm. As has been stated, binaural recordings use interaural differences, pinna filtering, and head/body shadowing to capture the acoustic structure of a listener.

It must be acknowledged that morphological differences between the ears used for recording and the ears of the subjects may have some minor adverse effects on the acoustic accuracy of these recordings. It is well known that listeners have differently shaped pinnae, differences in width between the two ears, and differences in head and body sound-attenuating properties that will affect changes to acoustic structure (for reviews, see Blauert, 1997/1999; Gilkey \& Anderson, 1997). However, although these head-related transfer functions (HRTFs) have been found to affect localization in the median plane and, particularly, within the cone of confusion, little performance degradation has been found in distance judgments when in-ear binaural recordings have been used (Minnaar et al., 2001). Furthermore, front-back errors tend to be slightly reduced for listeners using in-ear, rather than dummy head, recordings, because of the more accurate body reflection and absorption properties inherent with the in-ear method. Despite the problems 
caused by applying the HRTFs captured from one listener's ears and playing those recordings to other listeners, the spatial capture of binaural recordings is greatly improved over simple stereo recordings (e.g., Minnaar et al., 2001; Yost et al., 1996). The present results do add evidence to suggest the potential feasibility of this type of recording for future TTA research.

Interactions. A two-way interaction was found between speed and stimulus onset $\left[F(1,7)=11.269, M S_{\mathrm{e}}=\right.$ $0.027, p=.011$ (Greenhouse-Geisser corrected); see Figure 3]. This interaction seems to reflect the difficulty in performance with the $25-\mathrm{mph}$ velocity paired with the 3 sec stimulus onset stimulus. No interactions were found with the intrastimulus conditions or truncation lengths.

These results seem to suggest the flexible use of modal information for detection of TTA. The comparable performance in the normal and the alternating conditions suggests that changing the available media within an approach event may not degrade perception of TTA as long as the event information is continuous. However, it is acknowledged that the accuracy advantage with the normal and alternating presentations in the present experiment was relatively small. Thus, these comparisons were reevaluated in Experiment 2.

\section{EXPERIMENT 2 \\ Signal Versus Informational Continuity for TTA Perception}

In Experiment 1, the intermittent presentations differed from the alternating and normal presentations in two ways. In the intermittent condition, the availability of a signal (whether audio or visual) was interrupted at regular intervals, as was the overall availability of TTA information. In contrast, both the normal and the alter- nating presentations had a signal (of some type) and TTA information continuously available to the perceivers. Potentially, having periods of no available signal in the intermittent presentations may have been distracting to the subjects. This fact, rather than noninformative aspects of the intermittent presentations, might have accounted for the reduced accuracy with these stimuli. Experiment 2 was designed to examine this possibility, in addition to replicating the original intrastimulus effect. Specifically, in Experiment 2, the importance of having an available signal versus having an informative signal was tested by the inclusion of an intermittent-alternating (IA) condition. This IA condition involved alternating auditory and visual signals, but the auditory component did not provide appropriate TTA information (see Figure 4). In other words, this condition provided a continuous presentation of signal (cross-modally), as in the alternating condition, but a discontinuous stream of information, as in the intermittent condition.

If the IA condition is found to support performance equal to that for the alternating and normal conditions, this would suggest that simply the continuity of an available signal (cross-modally), whether informative or not, may be sufficient for TTA perception. However, if the IA condition is found to approximate the degraded performance of the intermittent condition in Experiment 1, this would suggest that a continuity of true TTA information across the modalities may be needed for accurate TTA judgments. In addition, Experiment 2 retested the three presentation conditions (alternating, intermittent, and normal) tested in Experiment 1, for purposes of replication.

\section{Method}

Subjects. Nine students ( 4 women and 5 men) from the University of California, Riverside, participated in this experiment for

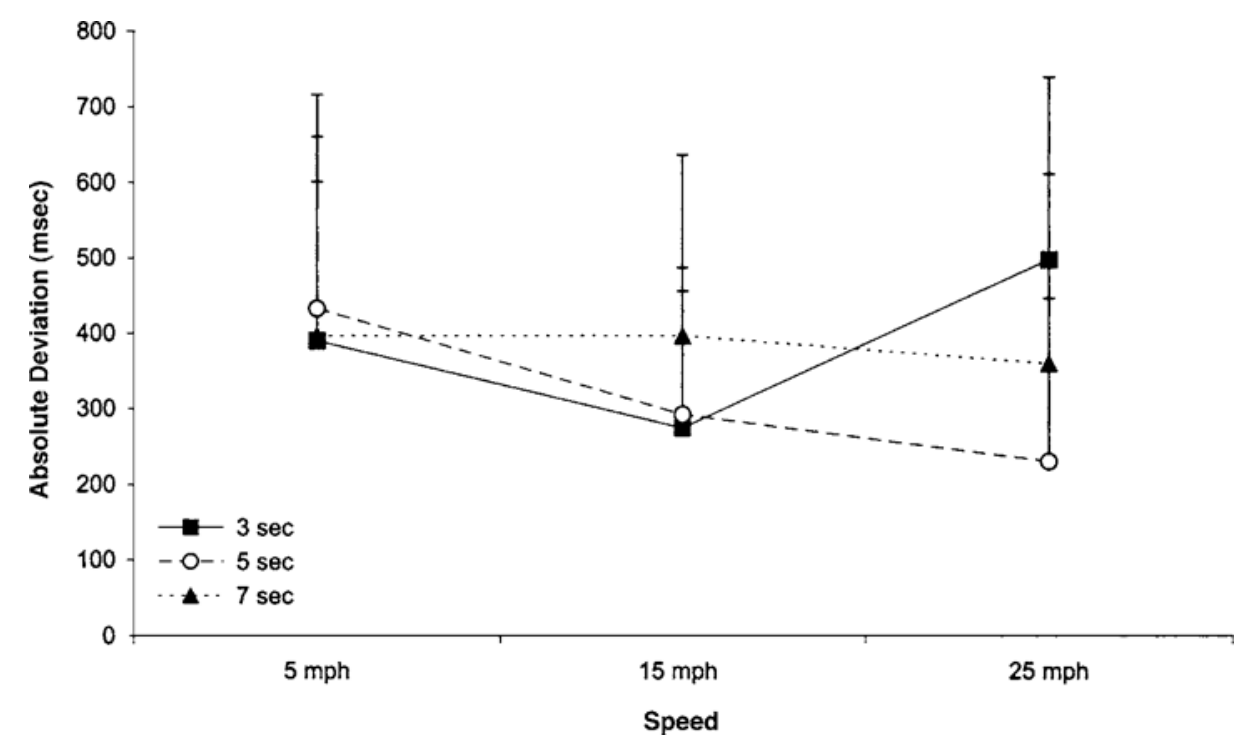

Figure 3. Absolute deviation of responses from passage time by speed and stimulus onset in Experiment 1. Error bars give the standard deviations of judgments. 


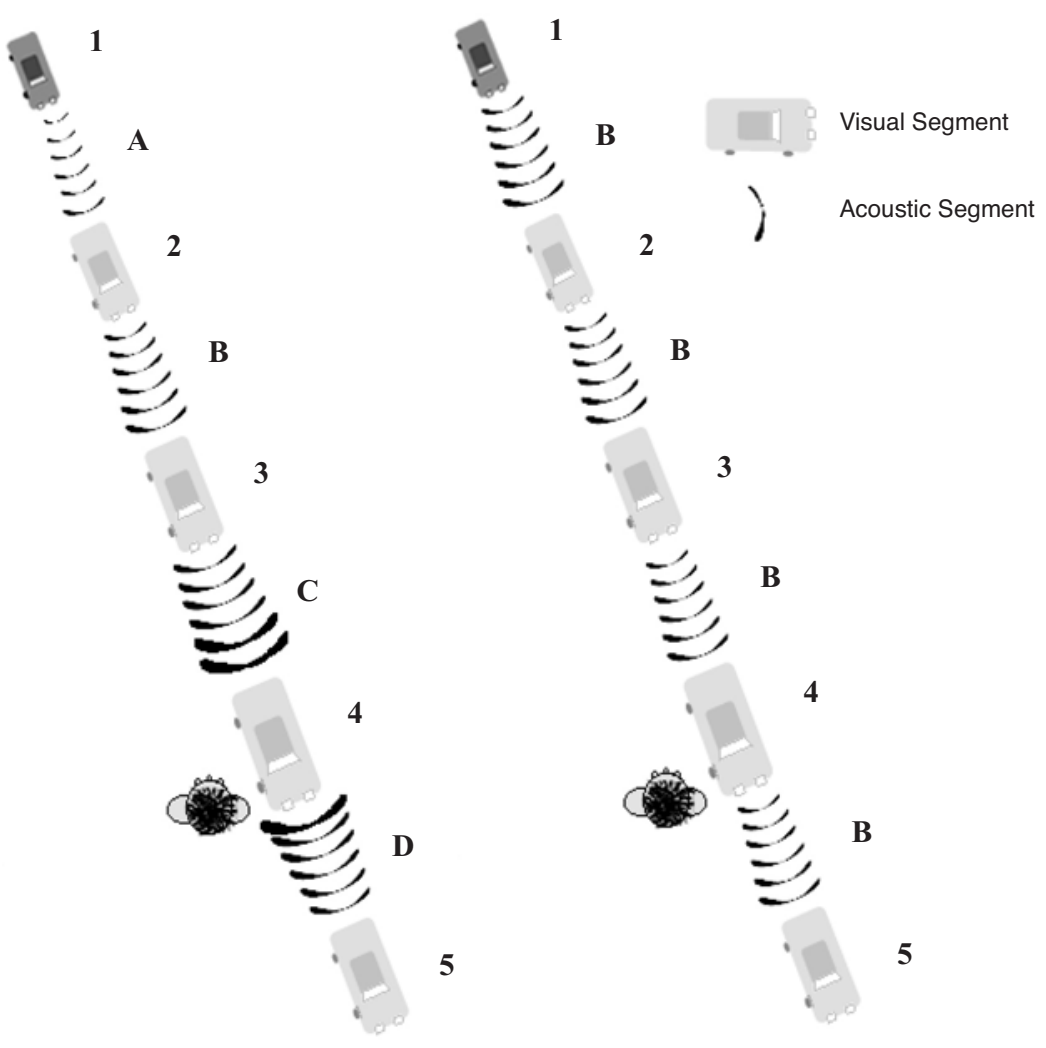

Figure 4. Schematic comparing the intermittent-alternating (IA; right) and the alternating (left) conditions. The numbers 1-5 represent the visual segments, and the letters A-D represent the audio segments. Note that in both the alternating and the IA schematics, the visual signal presents a progressively looming vehicle. However, only in the alternating condition does the audio signal progressively intensify across segments; in the IA condition, Segment $B$ is repeated between each visual segment.

class credit or for monetary reimbursement. All the subjects reported good hearing (without correction) and good vision (some with correction). None of the subjects had participated in the previous or any other TTA experiment.

Design. Independent variables for this experiment were speed (three levels: 5, 15, or $25 \mathrm{mph}$ [i.e., 8.05, 24.14, or $40.23 \mathrm{~km} / \mathrm{h}$ ]), stimulus onset (three levels: 3,5 , or $7 \mathrm{sec}$ before passage), truncation (three levels: passage or $1 \mathrm{sec}$ or $2 \mathrm{sec}$ before passage), and intrastimulus condition (four levels: normal, intermittent, alternating, or IA). All the variables were within subjects and were presented together randomly.

Materials. All the materials were the same as those used in the previous experiment, with the following exceptions. IA conditions were created such that informative visual signals were alternated with acoustic signals that were not informative about TTA (see Figure 4). These IA conditions were created by taking each of the approach stimuli from the alternating condition and replacing the auditory components with a single 500-msec audio segment, repeatedly. This replacement segment indicated an approach from 3.0 to $2.5 \mathrm{sec}$ prior to arrival, congruent with the speed of the visual signal. This acoustic segment was repeated between each visual segment for each IA stimulus. Although this acoustic segment was consistent with the speed of approach, it was inconsistent with the distance of approach (excepting those that would have naturally preceded and followed the 3.0- to 2.5-sec acoustic segment) and were, therefore, uninformative for TTA (see Figure 4). An example of an IA condi- tion would present a visual segment of a vehicle approaching from 4.5 to $4.0 \mathrm{sec}$, then the auditory segment specifying approach from 3.0 to $2.5 \mathrm{sec}$, then the visual segment specifying approach from 3.5 to $3.0 \mathrm{sec}$, then the same auditory segment from 3.0 to $2.5 \mathrm{sec}$, then the visual segment from 2.5 to $2.0 \mathrm{sec}$, then the auditory segment from 3.0 to $2.5 \mathrm{sec}$, and so forth. During the audio presentation, the visual signal advanced $500 \mathrm{msec}$, as it did in the original alternating condition; however, the audio segment always presented the same uninformative 500-msec approach segment.

Procedure. The procedure was the same as that in Experiment 1, with the following addition. The subjects received three iterations of each of the 108 possible conditions ( 4 presentation conditions $X$ 3 speeds $\times 3$ truncation lengths $\times 3$ stimulus onsets), for 324 trials. Each experimental session lasted approximately 55-60 min.

\section{Results and Discussion}

In approximately $83 \%$ of all the responses, the amount of time before passage was underestimated. As was found in the previous experiment, this proportion of underestimation did not vary across the independent variables.

A repeated measures ANOVA on the absolute deviation scores was again used to determine the relative accuracy of judgments across conditions. As in Experiment 1 , judgments that were inaccurate by more than 
$2.5 \mathrm{sec}$ were removed from the analysis (fewer than $1 \%$ of the judgments).

Condition effects. Analysis of response accuracy revealed a main effect of condition type $[F(3,24)=6.004$, $M S_{\mathrm{e}}=0.124, p=.003$; see Figure 5]. Paired comparisons were used to test the differences between the condition types. The normal conditions were found to support more accurate performance than the intermittent conditions did $\left[F(1,8)=9.67, M S_{\mathrm{e}}=0.091, p=.005\right]$, the alternating conditions produced more accurate performance than the intermittent conditions $\operatorname{did}[F(1,8)=7.52$, $\left.M S_{\mathrm{e}}=0.091, p=.011\right]$, the IA conditions did not differ statistically from the intermittent conditions $[F(1,8)=$ $\left.0.016, M S_{\mathrm{e}}=0.091, p>.6\right]$, the normal conditions produced more accurate performance than the IA conditions $\operatorname{did}\left[F(1,8)=10.462, M S_{\mathrm{e}}=0.091, p=.004\right]$, the alternating conditions produced more accurate performance than the IA conditions did $\left[F(1,8)=8.225, M S_{\mathrm{e}}=\right.$ $0.091, p=.009]$, and the normal conditions did not differ statistically from the alternating conditions $[F(1,8)=$ $\left.0.134, M S_{\mathrm{e}}=0.091, p>.6\right]$. The size of the presentation effect is slightly larger than in the first experiment (94msec difference between the normal and alternating vs. the intermittent and IA conditions) and is similarly consistent. These data replicate the presentation effect found in Experiment 1.

The poorer performance found with the IA condition suggests that the informativeness of the alternating condition, and not the continuous presence of the signal, supported TTA judgments of the approaching object. As has been stated, the acoustic IA segments were similar in quality, but not in informational content, to those in the alternating condition. Thus, it seems that this acoustic information in the alternating conditions was useful for maintaining some continuing perception of the event across changes of the media.

One question about the IA stimuli is whether their acoustic segments are better construed as noninformative or misinformative. In other words, were the incorrect acoustic segments in the IA condition functionally ignored by the subjects, or were these segments salient, causing performance degradation as a result of their misleading content? Regarding the latter possibility, there were periods in each IA presentation when the acoustic segments were contradictory to the visual signals and indicated different TTA information. For example, at the onset of an IA trial, the acoustic segments would tend to indicate arrival before the visual did, whereas nearer the end of an IA trial, the visual segments tended to indicate TTA before the auditory did. At some midpoint, however, the visual and the acoustic segments did offer congruous TTA information, so that the visual and the acoustic segments were in agreement about the speed and position of the looming vehicle.

Although this question cannot be settled with the present experiments, there are a few indications that IA trials consisted of noninformative, rather than misinformative, acoustic segments. In terms of the level of performance, the IA conditions were quite similar to the intermittent conditions. Potentially adding misinformative segments would degrade performance, relative to the neutral, blank segments of the intermittent conditions.

Furthermore, if the aberrant acoustic signals were misinforming the subjects about TTA, the likelihood of overestimation would be predicted to increase. Consider that near the point of passage (in the IA conditions), the acoustic segments indicated a passage time later than that indicated by the visual segment. For example, an acoustic

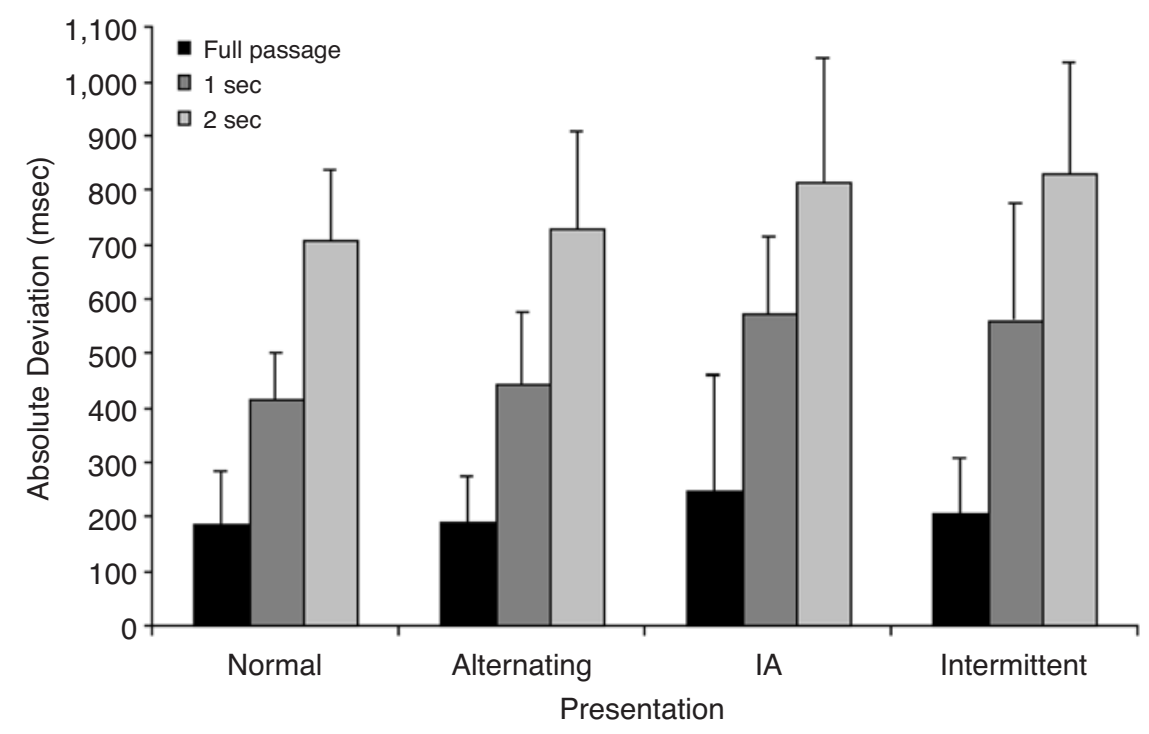

Figure 5. Absolute deviation of responses by condition type and truncation in Experiment 2. IA, intermittent-alternating. Error bars give the standard deviations of judgments. 
segment might indicate an arrival time of 3.0-2.5 sec, followed by a visual segment indicating an arrival time of $1.5-1.0 \mathrm{sec}$. The acoustic segment in this example (if salient) would misinform the subject that the actual arrival time was $1 \mathrm{sec}$ later than the arrival time indicated by the visual segment. Averaging these two estimates together (even assuming a lower salience for the acoustic segment) yields an overestimation of the actual TTA. However, this pattern was not borne out in the data. As has been stated, the proportion of underestimations did not vary by condition. Thus, the results seem more consistent with the hypothesis that the acoustic IA segments were noninformative and the subjects did not attend to these segments as separate TTA information.

These results add evidence to the interpretation offered in Experiment 1-namely, that substitution of the modality of presentation does not degrade TTA performance if the information for the event remains constant. The results in Experiment 2 replicated those in Experiment 1 by showing the relative equivalency of the normal and the alternating conditions and the poorer performance in the intermittent condition. Furthermore, the IA condition caused poorer performance, comparable to that in the intermittent condition. As has been stated, the IA conditions did not interrupt the stream of available media, but the acoustic segments did not inform the listeners about the progress of the approaching object. This informational interruption seemed to disrupt TTA perception in a way analogous to the effects of the signal (and informational) disruption in the intermittent condition.

Truncation, speed, and approach. A main effect of truncation was found. Longer truncations degraded performance accuracy $\left[F(2,16)=25.261, M S_{\mathrm{e}}=0.586\right.$, $p<.001$; see Figure 6]. Paired comparisons revealed that the full-length passages supported more accurate performance than both 1- and 2-sec truncations did [full length vs. $1 \mathrm{sec}, F(1,16)=22.341, M S_{\mathrm{e}}=0.586, p<$ .001 ; full length vs. $2 \mathrm{sec}, F(1,16)=86.168, M S_{\mathrm{e}}=$ $0.586, p<.001$; see Figure 6], and 1-sec truncations supported better performance than 2-sec truncations did $\left[1 \mathrm{sec}\right.$ vs. $2 \mathrm{sec}, F(1,16)=20.757, M S_{\mathrm{e}}=0.586, p<$ $.001]$. No main effect was found for speed or stimulus onset.

As in Experiment 1, a goodness-of-fit test was conducted to address whether performance with the full-length passage stimuli reflected accurate TTA performance. The observed data were binned into two categories: absolute deviation scores less than $200 \mathrm{msec}(0-199 \mathrm{msec})$ and absolute deviation scores greater than $200 \mathrm{msec}(200 \mathrm{msec}$ and over). Ideal performance for the full-length passages was assumed to be centered in the $0-$ to $199-\mathrm{msec}$ bin ( $90 \%$ of responses), with normally distributed errors spreading into the 200-msec-and-over bin. Unlike in Experiment 1, performance in Experiment 2 did not closely fit ideal performance $\left[\chi^{2}(2)=63.28, p<.05\right]$. This statistic suggests that the subjects may have had some difficulty in gauging the full-length passages under the presentation conditions in this experiment. Potentially, having two difficult conditions (the intermittent and the IA) may have contributed to the nonideal performance seen with the full-length passage stimuli. Although accuracy was not consistently within the ideal $200-\mathrm{msec}$ window, the subjects still demonstrated an ability to perform the task relatively well.

Interactions. A two-way interaction was found between speed and truncation $\left[F(1,32)=5.461, M S_{\mathrm{e}}=\right.$ $0.155, p<.05$ (Greenhouse-Geisser corrected); see Figure 6]. This interaction appears to have been a product of the relative performance with the 5-mph speed across truncation conditions. This speed was more accurately

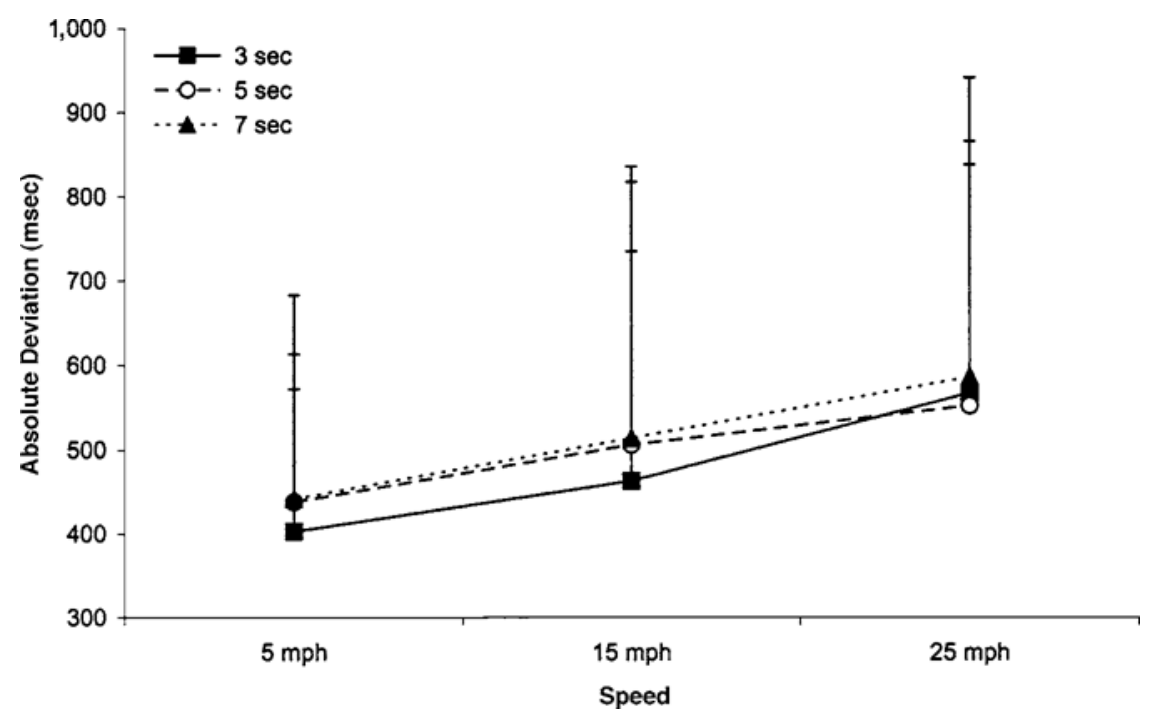

Figure 6. Absolute deviation of responses from passage time by speed and stimulus onset in Experiment 2. Error bars give the standard deviations of judgments. 
detected at the 1- and 2-sec truncations and was detected worse with the full-length passages.

An interaction was also found between condition and speed $\left[F(1,48)=4.761, M S_{\mathrm{e}}=0.085, p<.05\right.$ (Greenhouse-Geisser corrected)]. The difference between the continuous event presentations (normal and alternating) and the discontinuous event conditions (IA and intermittent) was found at the 15- and 25-mph speeds, but not at the 5-mph speed.

\section{GENERAL DISCUSSION}

The first experiment revealed that alternating the available media between vision and audition did not disrupt TTA judgments, relative to when both media were continuously present. The second experiment provided evidence that it was the cross-modal informational continuity that supported accurate performance in the modality-alternating condition, and not just the continuous presence of a signal available to either modality. Potentially, these results attest to the flexibility of TTA perception with regard to modality; in conditions for which there was continuous information for an approach event across modalities, intrastimulus modality switching did not degrade performance.

Certainly, it may be that the observed modal flexibility is limited to the range of conditions tested in these experiments. Perhaps with larger approach velocities or longer truncation values, alternating modalities would be more detrimental to TTA performance. Furthermore, modality alterations that are either shorter (assuming apparent motion is still disrupted at these intervals) or longer than the 500-msec alternations used in these experiments might be more disruptive to TTA performance. It could also be that in the contexts of more complicated tasks and/or stimuli (e.g., catching a projectile or judging TTA for observer approach), modality alternation would be substantially more disruptive.

Alternatively, previous research has suggested that the use of naturally occluding surfaces (e.g., an object moving behind an occluding tree) can diminish the deleterious effects of interrupting a visual presentation for a perceiver tracking an object's motion (Hancock \& Manser, 1997; Scholl \& Pylyshyn, 1999). Thus, it may be that the potential disruptions of intrastimulus changes in more extreme circumstances would be offset if natural occluders were used to remove access to a visual or an acoustic signal. Future research can be conducted to establish the range of conditions under which modality alternation does not disrupt TTA performance. However, within these constraints, an impressive facility for using the modalities was demonstrated in the present experiments. Across numerous combinations of speeds, stimulus onsets, and truncation values (all modeled on previous research), performance accuracy was not affected by alternating versus continuous modality stimuli. In this sense, the present experiments provide the first evidence that perception of TTA can be flexible with regard to modality.
Some speculation may be engaged in about how this modal flexibility is achieved by perceivers. One possibility lies with the nature of TTA information itself. Recall that the informational variable tau has been considered salient for TTA perception in multiple visual and auditory contexts. Generally speaking, tau can be considered a variable that specifies the amount of time before contact with a looming object would occur (Lee, 1976; Purdy, 1958; Schiff \& Detwiler, 1979; Tresilian, 1991). In most contexts, tau is defined as a systematic rate of change of some physical or energetic dimension over time. For example, in its original visual instantiation, tau was defined as $\tau=\theta /(d \theta / d \mathrm{t})$, where $\tau$ is the time to contact and $\theta$ equals the visual angle divided by a time-dependent derivative of the rate of the image's expansion (Gray \& Regan, 1998; Lee, 1990; Tresilian, 1991). However, in a number of studies, additional visual tau instantiations have been posited, derived from the expansion between two points locally, the expansion of whole bodies, and the lateral deviation of approaching objects from the focus of expansion when they are on bypass trajectories (for discussions, see Gray \& Regan, 1999; Heuer, 1993; Kaiser \& Mowafy, 1993; Tresilian, 1991).

Tau has also been shown to have several possible acoustic instantiations (Jenison, 1997; Lee, van der Weel, Hitchcock, Matejowski, \& Pettigrew, 1992; Neuhoff, 2001; Rosenblum, 1993; Shaw et al., 1991), including the rate of intensity change over time: $\tau=-2 I /(d I / d t)$, where $I$ is the average intensity over time divided by a time-dependent derivative of change in intensity over time. Acoustic tau derivations have also been discussed in the context of systematic frequency and spectral shifts (Lutfi \& Wang, 1999; Stoffregen \& Pittenger, 1995), for bat and human echolocation instantiated in the changes in the relative pulse-to-echo intensity and delay, as well as in the dilation of an acoustic solid angle (Lee et al., 1992; Rosenblum, Gordon, \& Jarquin, 2000).

In each of these visual and acoustic contexts, there is a unitary informational variable that may be defined as a systematic rate of change in some energy variable taken with regard to time (which can specify TTA). In this higher order sense, tau can be considered neutral information with regard to modality and could be used by a general TTA perceptual mechanism via multiple media arrays (e.g., visual, acoustic). In other words, for a perceptual function that is sensitive to tau's systematic rate of change, the specific energy - and modality - through which that change is conveyed would be relatively unimportant. For this type of function, assuming sufficient available information across media, a midstimulus change in modality would have relatively little effect on TTA judgments. In this sense, the concept of modality-neutral information could provide one explanation for the results observed in these experiments.

Examples of modality-neutral information and its potential salience have been discussed in other domains. Because of the relevance of this issue to the present experiments, some of this research will be discussed next. 


\section{Modality-Neutral Information}

Recent evidence in the speech perception literature suggests that speech information might best be construed as modality neutral (Kuhl \& Meltzoff, 1984; Rosenblum, 2004, 2005; Rosenblum \& Gordon, 2001; Summerfield, 1987). From this perspective, speech perception involves recovery of articulatory gestures via higher order kinematic informational variables that are instantiated as a structure in multiple arrays (acoustic, optic, tactile). In this sense, modality is functionally invisible to the speech function, because the mechanism is sensitive to the modality-neutral patterns of energy. Moreover, cross-modal integration is considered to be a consequence of the information itself: If the information is modality neutral, the modal streams are functionally never separate. Put another way, the cross-modal streams cohere because they are structured by exactly the same event in exactly the same way.

To be clear, the use of multiple modalities and modalityneutral information does not imply that the information will be equally available across media or that perceivers will have equal aptitude for using that information across all modalities. Certainly for speech, it is often the case that the acoustic medium facilitates perception better than the visual medium does. The claim is simply that for the speech function, the salient information takes a form (e.g., articulatory kinematics) that is neutral with regard to modality (Rosenblum, 2004, 2005; Rosenblum \& Gordon, 2001).

Support for the use of modality-neutral information in speech perception has been evidenced by the universality, automaticity, and immediacy of audiovisual speech integration (Fowler \& Dekle, 1991; Green, 1998; Massaro, Cohen, Gesi, Heredia, \& Tsuzaki, 1993; Rosenblum, Schmuckler, \& Johnson, 1997), by the apparent informational similitude across auditory and visual speech streams (Munhall \& Vatikiotis-Bateson, 1998; Rosenblum \& Saldaña, 1998; Rosenblum et al., 2002; see Rosenblum, 2005, for a review), and by the neural responsiveness of the auditory cortex to unimodal visible speech information (Calvert et al., 1997; MacSweeney, Amaro, Calvert, \& Campbell, 2000; MacSweeney et al., 2002; but see Bernstein et al., 2002). The concept of modality-neutral information is also consistent with many theories of perceptual development (Kuhl \& Meltzoff, 1984; Lewkowicz \& Turkewitz, 1980; Marks, 1978; Maurer, 1993), general perception (Gibson, 1966, 1979), and neurophysiology (Eimer, 2001; Ladavas, Pavani, \& Farne, 2001; Laurienti et al., 2002; Macaluso, Frith, \& Driver, 2000; Maunsell, Nealy, Sclar, \& DePriest, 1989; Pavani, Meneghello, \& Ladavas, 2001; Shams, Kamitani, Thompson, \& Shimojo, 2001; Shimojo \& Shams, 2001; Zangaladze, Epstein, Grafton, \& Sathian, 1999). This type of evidence has led some theorists to conclude that the sensory brain is organized around multimodal input (e.g., Stein \& Meredith, 1993).

Returning to the present results, if a tau variable can be used for TTA perception and can be instantiated in multiple modalities as a systematic change of some energy over time, it could be considered a modality-neutral form of information. Moreover, if the mechanism involved in detecting TTA information is sensitive to a modality-neutral variable, changes in modality would have a minimal cost for TTA perception, as long as continuous tau information is present. If tau can be instantiated as a multimodal energy pattern, a modality-neutral information interpretation is consistent with the present results.

As has been discussed for speech, the modality-neutral hypothesis for TTA does not suggest that all modalities will support equal performance in all circumstances. Such factors as the ability of a medium to support tau information, differential peripheral sensory sensitivities, and subjects' ability to attend to tau information in a given modality will influence the degree to which a modality can support tau judgment accuracy. The claim is not that tau information will be equally available across modalities and stimulus contexts but that the salient information that is used by the tau mechanism takes a form that is neutral with regard to modality.

Although we consider the present results supportive of a modality-neutral tau function, these experiments constitute a first attempt to directly test the hypothesis in a TTA context. As has been found for speech, a preponderance of converging evidence from behavioral and neurophysiological research will be necessary to establish whether the salient information for TTA can be considered modality neutral.

The modality-neutral hypothesis is only one interpretation of the modal flexibility observed in the present research. It is likely that other theories of cross-modal and general information integration could be fitted to our results (see Gordon, 2002, for a discussion). Information integration models that use Bayesian algorithms (Jacobs \& Fine, 1999; Massaro, 1992, 1998), strong and weak fusion models (Bülthoff \& Mallot, 1988; Landy, Maloney, Johnston, \& Young, 1995; Young, Landy, \& Maloney, 1993), and veto models (Bülthoff \& Mallot, 1988; Turner, Braunstein, \& Andersen, 1997) could be embellished to make predictions about the TTA performance in these experiments. Future research can be designed to test these and other integration theories in their predictive power for modality-alternating stimulus experiments (see also Gordon, 2002).

An additional question is whether these separate modal streams require separate attentional resources (e.g., Tambiev, Medvedev, \& Tepina, 1993; Wickens, 2002; Wickens, Sandry, \& Vidulich, 1983) or whether the similarity of the information across modalities reduces those potential costs (Chen, 1998). It has been posited that separate resources are available for each perceptual modality and that attention may be a time-shared function (Wickens, 2002). The present results are commensurate with that speculation, in that no obvious modality-switching costs were observed. However, this is also an issue that requires additional study. 


\section{Evaluation of Stimulus Effectiveness}

As has been discussed, a number of novel stimulus techniques were implemented in the present research. Although the range of approach velocities and truncation times were modeled closely on those in other TTA experiments, many aspects of the present experiments differed from those used in the established TTA literature. For example, the visual stimuli were filmed (videotaped) rather than animated, as is more commonly done (e.g., DeLucia \& Liddell, 1998; DeLucia \& Novak, 1997; Gray \& Regan, 1998, 1999; Heuer, 1993; Regan \& Beverley, 1979). Also, the present experiments were the first to use binaural recordings for the auditory stimulus component. Third, audiovisual TTA has been studied only infrequently (e.g., Gordon, 2003; Morrongiello \& Fenwick, 1991; Pickens, 1994; Schiff \& Oldak, 1990). Finally and most obviously, our experiments are novel in using stimuli for which the audio and visual signals were intermittent and alternating. Although it was not the central goal of these experiments, our results do allow some evaluation of these stimulus techniques in light of results from the established TTA literature.

The findings in these experiments were largely consistent with those in both the visual and the auditory TTA literatures. Truncation was generally found to negatively influence performance, and the magnitude of the errors tended to increase with larger truncation lengths. This result has been extensively replicated in both auditory and visual TTA research (for reviews, see Hancock \& Manser, 1998; Rosenblum, 1993).

However, the present data are slightly aberrant in that performance accuracy with the normal audiovisual stimuli ( $250 \mathrm{msec}$ absolute deviation) was somewhat poorer than that typically shown in the unimodal visual TTA literature ( 200 msec; e.g., Cavallo \& Laurent, 1988; Hancock \& Manser, 1997; Schiff \& Detwiler, 1979; Schiff \& Oldak, 1990), although better than that normally shown with unimodal acoustic stimuli ( $\sim 500 \mathrm{msec}$; e.g., Gordon, 2003; Rosenblum, Gordon, \& Wuestefeld, 2000; Schiff \& Oldak, 1990). Particularly in Experiment 2, performance with the full-length passages was somewhat poorer than expected. There are a few factors that may have contributed to this finding. In the present research, a wide range of presentation times was used for testing. Presentations were as short as $1 \mathrm{sec}$ and as long as $9 \mathrm{sec}$, depending on the stimulus onset and truncation combination. Potentially, using such a wide range of approach values may have contributed to this poorer performance. Previous research in rhythmic expectancies has shown that using a wide range of event durations can increase variability in performance (Barnes \& Jones, 2000).

A second possible explanation for the larger deviations in the present data is the use of absolute deviation scores as the dependent measure. In many other TTA studies, constant error and variable error have been used as the measures of performance. Had these measures been used for the present experiments, the errors reported would have been reduced. In both experiments, judgments were found to underestimate the arrival time of the approaching object approximately $84 \%$ of the time. The $16 \%$ of overestimation judgments contributed an increase in the total error reported, because of our use of an absolute deviation measure (unsigned error). For studies that have reported signed error, it is difficult to determine how much the total error has been reduced by overestimation judgments. Having analyzed the data with an unsigned measure thus may have contributed to the slight difference in performance accuracy between the present results and previous unimodal visual TTA findings.

Despite this difficulty, the present findings indicate a general consistency with typical TTA results and suggest the viability of our stimulus techniques for future research. These techniques may allow more exploration of the governing informational variables supporting TTA perception, as well as tests of event continuity across periodic informational and media interruptions.

\section{REFERENCES}

Andersen, G. J., Saidpour, A., \& Braunstein, M. L. (1998). Effects of collimation on perceived layout in 3-D scenes. Perception, 11, 1305-1315.

Anderson, A. J., \& VINGRYs, A. J. (2000). Interactions between flicker thresholds and luminance pedestals. Vision Research, 40, 2579-2588.

BARnes, R., \& Jones, M. R. (2000). Expectancy, attention, and time. Cognitive Psychology, 41, 254-311.

Bernstein, L. E., Auer, E. T., Moore, J. K., Ponton, C., Don, M., \& SINGH, M. (2002). Visual speech perception without primary cortex activation. NeuroReport, 13, 311-315.

Blauert, J. (1999). Progress and trends since 1982. In J. Blauert, Spatial hearing: The psychophysics of human sound localization (J. S. Allen, Trans.) (pp. 369-409). Cambridge, MA: MIT Press. (Original work published 1997)

Bülthoff, H. H., \& MAllot, H. A. (1988). Integration of depth modules: Stereo and shading. Journal of the Optical Society of America A, 5, 1749-1758.

Cabe, P. A., \& Pittenger, J. B. (2000). Human sensitivity to acoustic information from vessel filling. Journal of Experimental Psychology: Human Perception \& Performance, 26, 313-324.

Caelli, T., \& Porter, D. (1980). On difficulties in localizing ambulance sirens. Human Factors, 22, 719-724.

Calvert, G. A., Bullmore, E., Brammer, M. J., Campbell, R., Iversen, S. D., WoodrufF, P., McGuire, P., Williams, S., \& David, A. S. (1997). Silent lipreading activates the auditory cortex. Science, 276, 593-596.

Cavallo, V., \& Laurent, M. (1988). Visual information and skill level in time-to-collision estimation. Perception, 17, 623-632.

CHase, W. D. (1970). Evaluation of several TV display system configurations for visual simulation of the landing approach. IEEE Transactions on Man-Machine Systems, 11, 140-149.

CHEN, Z. (1998). Switching attention within and between objects: The role of subjective organization. Canadian Journal of Experimental Psychology, 52, 7-16.

Delucia, P. R., Kaiser, M. K., Bush, J. M., Meyer, L. E, \& Sweet, B. T. (2003). Information integration in judgements of time to contact. Quarterly Journal of Experimental Psychology, 56A, 1165 1189.

DeLucia, P. R., \& Liddell, G. W. (1998). Cognitive motion extrapolation and cognitive clocking in prediction motion. Journal of Experimental Psychology: Human Perception \& Performance, 24, 901-914.

DeLucia, P. R., \& NovaK, J. B. (1997). Judgments of relative time-tocontact of more than two approaching objects: Toward a method. Perception \& Psychophysics, 59, 913-928. 
EImer, M. (2001). Crossmodal links in spatial attention between vision, audition, and touch: Evidence from event-related brain potentials. Neuropsychologia, 39, 1292-1303.

Fowler, C. A., \& DeKLE, D. J. (1991). Listening with eye and hand: Cross-modal contributions to speech perception. Journal of Experimental Psychology: Human Perception \& Performance, 17, 816-828.

Gibson, J. J. (1966). The senses considered as perceptual systems. Boston: Houghton Mifflin.

Gibson, J. J. (1979). The ecological approach to visual perception. Hillsdale, NJ: Erlbaum.

GILKEY, R. H., \& ANDERSON, T. R. (1997). Binaural and spatial hearing in real and virtual environments. Mahwah, $\mathrm{NJ}$ : Erlbaum.

GoRDON, M. S. (2002). Audiovisual time-to-arrival judgments: Testing the primacy of multimodal integration. Unpublished doctoral dissertation, University of California, Riverside.

Gordon, M. S. (2003). Multimodal enhancement of audiovisual timeto-arrival judgments. Paper presented at the meeting of the 4th International Multisensory Research Forum, Hamilton, Ontario.

GraY, R., \& REgAN, D. (1998). Accuracy of estimating time to collision using binocular and monocular information. Vision Research, $\mathbf{3 8}$ 499-512.

Gray, R., \& Regan, D. (1999). Do monocular time-to-collision estimates necessarily involve perceived distance? Perception, 28, 1257 1264.

GreEN, K. P. (1998). The use of auditory and visual information during phonetic processing: Implications for theories of speech perception. In R. Campbell, B. Dodd, \& D. Burnham (Eds.), Hearing by eye II: Advances in the psychology of speechreading and auditory-visual speech (pp. 3-25). Hove, U.K.: Psychology Press.

Guski, R. (1992). Acoustic tau: An easy analogue to visual tau? Ecological Psychology, 4, 189-197.

Hancock, P. A., \& Manser, M. P. (1997). Time-to-contact: More than tau alone. Ecological Psychology, 9, 265-297.

Hancock, P. A., \& Manser, M. P. (1998). Time-to-contact. In A.-M. Feyer \& A. Williamson (Eds.), Occupational injury: Risk, prevention, and intervention (pp. 44-58). Bristol, PA: Taylor \& Francis.

HaWley, M. L., Litovsky, R. Y., \& Colburn, H. S. (1999). Speech intelligibility and localization in a multi-source environment. Journal of the Acoustical Society of America, 105, 3436-3448.

Heuer, H. (1993). Estimates of time to contact based on changing size and changing target vergence. Perception, 22, 549-563.

Hock, H. S., Kogan, K., \& Espinoza, J. K. (1997). Dynamic, statedependent thresholds for the perception of single-element apparent motion: Bistability from local cooperativity. Perception \& Psychophysics, 59, 1077-1088.

JACOBS, R. A., \& Fine, I. (1999). Experience-dependent integration of texture and motion cues to depth. Vision Research, 39, 4062-4075.

JENISON, R. L. (1997). On acoustic information for motion. Ecological Psychology, 9, 131-151.

KaIser, M. K., \& Hecht, H. (1995). Time-to-passage judgments in nonconstant optical flow fields. Perception \& Psychophysics, 57, 817-825.

KaISER, M. K., \& MowaFy, L. (1993). Optical specification of time-topassage: Observers' sensitivity to global tau. Journal of Experimental Psychology: Human Perception \& Performance, 19, 1028-1040.

Kuhl, P. K., \& Meltzoff, A. N. (1984). The intermodal representation of speech in infants. Infant Behavior \& Development, 7, 361-381.

Ladavas, E., PaVani, F., \& Farne, A. (2001). Auditory peripersonal space in humans: A case of auditory-tactile extinction. Neurocase, 7 , $97-103$.

Landy, M. S., Maloney, L. T., Johnston, E. B., \& Young, M. (1995). Measurement and modeling of depth cue combination: In defense of weak fusion. Vision Research, 35, 389-412.

Laurienti, P. J., Burdette, J. H., Wallace, M. T., Yen, Y.-F., Field, A. S., \& SteIn, B. E. (2002). Deactivation of sensory-specific cortex by cross-modal stimuli. Journal of Cognitive Neuroscience, 14, 420429.

LEE, D. N. (1976). A theory of visual control of braking based on information about time-to-collision. Perception, 5, 437-459.

LEE, D. N. (1990). Getting around with light or sound. In R. Warren \& A. H. Wertheim (Eds.), Perception and control of self-motion (pp. 487505). Hillsdale, NJ: Erlbaum.
Lee, D. N., van der Weel, F. R., Hitchcock, T. Matejowski, E. \& Pettigrew, J. D. (1992). Common principle of guidance by echolocation and vision. Journal of Comparative Physiology A, 171, 563-571.

LEWKowicz, D. J., \& TuRKewiTz, G. (1980). Cross-modal equivalence in early infancy: Auditory-visual intensity matching. Developmental Psychology, 16, 597-607.

LUTFI, R. A., \& WANG, W. (1999). Correlational analysis of acoustic cues for the discrimination of auditory motion. Journal of the Acoustical Society of America, 106, 919-928.

Macaluso, E., Frith, C. D., \& Driver, J. (2000). Modulation of human visual cortex by crossmodal spatial attention. Science, 289, 1206-1208

MacSweeney, M., Amaro, E., Calvert, G. A., \& Campbell, R. (2000) Silent lipreading in the absence of scanner noise: An event-related fMRI study. NeuroReport, 11, 1729-1733.

MacSweeney, M., Calvert, G. A., Campbell, R., McGuire, P. K., David, A. S., Williams, S. C., Woll, B., \& Brammer, M. J. (2002). Speechreading circuits in people born deaf. Neuropsychologia, 40, 801-807.

Marks, L. E. (1978). The unity of the senses. New York: Academic Press.

Massaro, D. W. (1992). Broadening the domain of the fuzzy logical model of perception. In H. L. Pick, Jr., \& P. W. van den Broek (Eds.) Cognition: Conceptual and methodological issues (pp. 51-84). Washington, DC: American Psychological Association Press.

Massaro, D. W. (1998). Perceiving talking faces: From speech perception to a behavioral principle. Cambridge, MA: MIT Press.

Massaro, D. W., Cohen, M. M., Gesi, A., Heredia, R., \& Tsuzaki, M (1993). Bimodal speech perception: An examination across languages. Journal of Phonetics, 21, 445-478.

Maunsell, J. H. R., Nealy, T. A., Sclar, G., \& DePriest, D. D (1989). Representation of extraretinal information in monkey visual cortex. In D. M.-K. Lam \& C. D. Gilbert (Eds.), Neural mechanisms of visual perception: Proceedings of the Retina Research Foundation Symposia. The Woodlands, TX: Portfolio Publishing.

MAURER, D. (1993). Neonatal synesthesia: Implication for the processing of speech and faces. In B. de Boysson-Bardies, S. de Schonen, P. Jusczyk, \& J. Morton (Eds.), Developmental neurocognition: Speech and face processing in the first year of life (pp. 109-124). Dordrecht: Kluwer.

McLeod, R. W., \& Ross, H. E. (1983). Optic-flow and cognitive factors in time-to-collision estimates. Perception, 12, 417-423.

Minnaar, P., Olesen, S. K., Christensen, F., \& Møller, H. (2001). Localization with binaural recordings from artificial and human heads. Journal of the Audio Engineering Society, 49, 323-336.

Morrongiello, B. A., \& Fenwick, K. D. (1991). Infants' coordination of auditory and visual depth information. Journal of Experimental Child Psychology, 52, 277-296.

Munhall, K. G., \& Vatikiotis-Bateson, E. (1998). The moving face during speech communication. In R. Campbell, B. Dodd, \& D. Burnham (Eds.), Hearing by eye II: Advances in the psychology of speechreading and auditory-visual speech (pp. 123-139). Hove, U.K.: Psychology Press.

Neuhoff, J. G. (2001). An adaptive bias in the perception of looming auditory motion. Ecological Psychology, 13, 87-110.

Pavani, F., Meneghello, F., \& Ladavas, E. (2001). Deficit of auditory space perception in patients with visuospatial neglect. Neuropsychologia, 39, 1401-1409.

PetersiK, J. T. (1989). The two-process distinction in apparent motion. Psychological Bulletin, 106, 107-127.

PICKENS, J. (1994). Perception of auditory-visual distance relations by 5-month-old infants. Developmental Psychology, 30, 537-544.

PRESSING, J. (1998). Error correction processes in temporal pattern production. Journal of Mathematical Psychology, 42, 63-101.

PURDY, W. C. (1958). The hypothesis of psychophysical correspondence in space perception (Doctoral dissertation, Cornell University, 1958). Dissertation Abstracts International, 19, 1454-1455.

Regan, D., \& BeverLey, K. I. (1979). Binocular and monocular stimuli for motion in depth: Changing-disparity and changing-size feed the same motion-in-depth stage. Vision Research, 19, 1331-1342.

Rosenblum, L. D. (1993). Acoustical information for controlled collisions. In A. Schick (Ed.), Contributions to psychological acoustics (pp. 303-322). Oldenburg, Germany: Bibliotheks. 
Rosenblum, L. D. (2004). Perceiving articulatory events: Lessons for an ecological psychoacoustics. In J. G. Neuhoff (Ed.), Ecological psychoacoustics (pp. 219-248). Amsterdam: Elsevier.

Rosenblum, L. D. (2005). The primacy of multimodal speech perception. In D. Pisoni \& R. Remez (Eds.), Handbook of speech perception (pp. 51-78). Malden, MA: Blackwell.

Rosenblum, L. D., Carello, C., \& Pastore, R. E. (1987). Relative effectiveness of three stimulus variables for locating a moving sound source. Perception, 16, 175-186.

Rosenblum, L. D., \& Gordon, M. S. (2001). The generality of specificity: Some lessons from audiovisual speech. Behavioral \& Brain Sciences, 24, 239-240.

Rosenblum, L. D., Gordon, M. S., \& Jarquin, L. (2000). Echolocation by moving and stationary listeners. Ecological Psychology, 12, 181-206.

Rosenblum, L. D., Gordon, M. S., \& Wuestefeld, A. P. (2000). Effects of performance feedback and feedback withdrawal on auditory looming perception. Ecological Psychology, 12, 273-291.

Rosenblum, L. D., \& SaldaÑa, H. M. (1998). Time-varying information for visual speech perception. In R. Campbell, B. Dodd, \& D. Burnham (Eds.), Hearing by eye II: Advances in the psychology of speechreading and auditory-visual speech (pp. 61-81). Hove, U.K.: Psychology Press.

Rosenblum, L. D., Schmuckler, M. A., \& Johnson, J. A. (1997). The McGurk effect in infants. Perception \& Psychophysics, 59, 347-357.

Rosenblum, L. D., Wuestefeld, A. P., \& Salda ̃̃a, H. M. (1993). Auditory looming perception: Influences on anticipatory judgments. Perception, 22, 1467-1482.

Rosenblum, L. D., Yakel, D. A., Baseer, N., Panchal, A., NorDARSE, B. C., \& NiehUS, R. P. (2002). Visual speech information for face recognition. Perception \& Psychophysics, 64, 220-229.

SCHIFF, W., \& DetwiLER, M. L. (1979). Information used in judging impending collision. Perception, 8, 647-658.

Schiff, W., \& OLDAK, R. (1990). Accuracy of judging time to arrival: Effects of modality, trajectory, and gender. Journal of Experimental Psychology: Human Perception \& Performance, 16, 303-316.

Scholl, B. J., \& Pylyshyn, Z. W. (1999). Tracking multiple items through occlusion: Clues to visual objecthood. Cognitive Psychology, 38, 259-290.

Shams, L., Kamitani, Y., Thompson, S., \& Shimojo, S. (2001). Sound alters visual evoked potentials in humans. NeuroReport, 12, 3849-3852.

Shaw, B. K., McGowan, R. S., \& Turvey, M. T. (1991). An acoustic variable specifying time-to-contact. Ecological Psychology, 3, 253-261.

Shimojo, S., \& Shams, L. (2001). Sensory modalities are not separate modalities: Plasticity and interactions. Current Opinion in Neurobiology, 11, 505-509.

Sidaway, B., Fairweather, M., Sekiya, H., \& McNitt-Ray, J. (1996). Time-to-collision estimate in a simulated driving task. Human Factors, 38, 101-114.

Stein, B. E., \& Meredith, M. A. (1993). The merging of the senses. Cambridge, MA: MIT Press.

Stoffregen, T. A., \& Pittenger, J. B. (1995). Human echolocation as a basic form of perception and action. Ecological Psychology, 7, 181-216.

Summerfield, A. Q. (1987). Some preliminaries to a comprehensive account of audio-visual speech perception. In B. Dodd \& R. Campbell (Eds.), Hearing by eye: The psychology of lip-reading (pp. 3-51). Hillsdale, NJ: Erlbaum.
TaKahashi, M., \& Maruyama, K. (1977). Visual masking function to flickering stimulus in "blank-flick" experiment. Tohoku Psychologica Folia, 36, 134-137.

Tambiev, A. E., Medvedev, S. D., \& Tepina, M. V. (1993). EeGcorrelates of switching of sensory attention. Psikhologicheskiy Zhurnal, 14, 65-70.

Tresilian, J. R. (1991). Empirical and theoretical issues in the perception of time to contact. Journal of Experimental Psychology: Human Perception \& Performance, 17, 865-876.

Turner, J., Braunstein, M. L., \& Andersen, G. J. (1997). Relationship between binocular disparity and motion parallax in surface detection. Perception \& Psychophysics, 59, 370-380.

WICKENS, C. D. (2002). Multiple resources and performance prediction. Theoretical Issues in Ergonomics Science, 3, 159-177.

Wickens, C. D., SANDry, D., \& Vidulich, M. (1983). Compatibility and resource competition between modalities of input, output, and central processing. Human Factors, 25, 227-248.

Wiegrebe, L., \& Krumbholz, K. (1999). Temporal resolution and temporal masking properties of transient stimuli: Data and an auditory model. Journal of the Acoustical Society of America, 105, 27462756.

Yost, W. A., Dye, R. H., JR., \& Sheft, S. (1996). A simulated “cocktail party" with up to three sound sources. Perception \& Psychophysics, 58, 1026-1036.

YounG, M. J., LANDY, M. S., \& MALONEY, L. T. (1993). A perturbation analysis of depth perception from combinations of texture and motion cues. Vision Research, 33, 2685-2696.

Zangaladze, A., Epstein, C. M., Grafton, S. T., \& Sathian, K. (1999). Involvement of visual cortex in tactile discrimination of orientation. Nature, 401, 587-590.

\section{NOTE}

1. The general term TTA has been selected for use throughout this article, instead of the more specific terms time-to-collision (TTC) or timeto-passage (TTP). For the latter two terms, TTC refers exclusively to those events in which an object is approaching a perceiver on a collision course (e.g., Cavallo \& Laurent, 1988; Gray \& Regan, 1999; Hancock $\&$ Manser, 1998; Schiff \& Detwiler, 1979), whereas TTP describes an event in which an object is approaching a perceiver on a bypass trajectory (e.g., Kaiser \& Mowafy, 1993; Rosenblum, Carello, \& Pastore, 1987; Schiff \& Oldak, 1990). Research has tested detection of TTC versus TTP (e.g., Schiff \& Oldak, 1990). Passage trajectories of an object moving within $5 \mathrm{~m}$ of an observer $\left(<8^{\circ}\right.$ visual eccentricity) were found to be judged with the same accuracy as head-on TTC presentations. Increasing the visual eccentricity in TTP $\left(>10^{\circ}\right)$ has been found to slightly improve performance accuracy (Schiff \& Oldak, 1990). This behavioral distinction between TTP events and the similarity of near-passage TTP judgments to TTC ones prompted the use of a more general term: TTA. TTA is specific to those events that involve an approaching object that may collide with or narrowly miss a perceiver. In the following experiments, TTA is used to describe the near-passage approach trajectories $\left(<5^{\circ}\right.$ visual eccentricity).

(Manuscript received July 8, 2003; revision accepted for publication August 9, 2004.) 